PREPARED FOR THE U.S. DEPARTMENT OF ENERGY, UNDER CONTRACT DE-AC02-76CH03073

PPPL-3472

PPPL-3472

UC-70

Tokamak Simulation Code Modeling of NSTX

by

S.C. Jardin, S. Kaye, J. Menard, C. Kessel, and A.H. Glasser

July 2000

积PPL

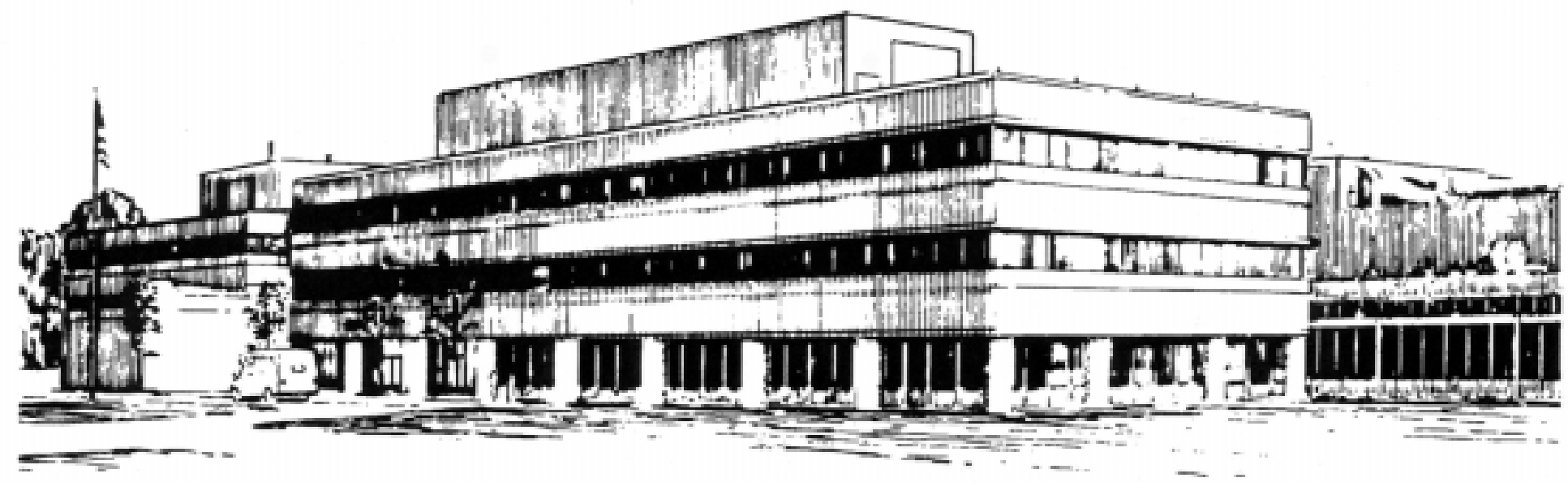

PRINCETON PLASMA PHYSICS LABORATORY PRINCETON UNIVERSITY, PRINCETON, NEW JERSEY 


\section{PPPL Reports Disclaimer}

This report was prepared as an account of work sponsored by an agency of the United States Government. Neither the United States Government nor any agency thereof, nor any of their employees, makes any warranty, express or implied, or assumes any legal liability or responsibility for the accuracy, completeness, or usefulness of any information, apparatus, product, or process disclosed, or represents that its use would not infringe privately owned rights. Reference herein to any specific commercial product, process, or service by trade name, trademark, manufacturer, or otherwise, does not necessarily constitute or imply its endorsement, recommendation, or favoring by the United States Government or any agency thereof. The views and opinions of authors expressed herein do not necessarily state or reflect those of the United States Government or any agency thereof.

\section{Availability}

This report is posted on the U.S. Department of Energy's Princeton Plasma Physics Laboratory Publications and Reports web site in Calendar Year 2000. The home page for PPPL Reports and Publications is: http://www.pppl.gov/pub_report/

DOE and DOE Contractors can obtain copies of this report from:

U.S. Department of Energy

Office of Scientific and Technical Information

DOE Technical Information Services (DTIS)

P.O. Box 62

Oak Ridge, TN 37831

Telephone: (865) 576-8401

Fax: (865) 576-5728

Email: reports@adonis.osti.gov

This report is available to the general public from:

National Technical Information Service

U.S. Department of Commerce

5285 Port Royal Road

Springfield, VA 22161

Telephone: $1-800-553-6847$ or

(703) $605-6000$

Fax: (703) 321-8547

Internet: http://www.ntis.gov/ordering.htm 


\title{
Tokamak Simulation Code Modeling of NSTX
}

\author{
S.C. Jardin, S. Kaye, J. Menard, C. Kessel \\ Princeton Plasma Physics Laboratory \\ A.H. Glasser \\ Los Alamos National Laboratory
}

The Tokamak Simulation Code [TSC] is widely used for the design of new axisymmetric toroidal experiments. In particular, TSC was used extensively in the design of the National Spherical Torus eXperiment [NSTX]. We have now benchmarked TSC with initial NSTX results and find excellent agreement for plasma and vessel currents and magnetic flux loops when the experimental coil currents are used in the simulations. TSC has also been coupled with a ballooning stability code and with DCON to provide stability predictions for NSTX operation. TSC has also been used to model initial CHI experiments where a large poloidal voltage is applied to the NSTX vacuum vessel, causing a force-free current to appear in the plasma. This is a phenomenon that is similar to the "plasma halo current" that sometimes develops during a plasma disruption.

TSC models the evolution of free-boundary axisymmetric toroidal plasma on the resistive and energy confinement time scales. The plasma equilibrium and field evolution equations are solved on a two-dimensional Cartesian grid. Boundary conditions between plasma/vacuum/conductors are based on the fact that the poloidal flux is continuous across interfaces. The surface-averaged transport equations for the pressures and densities are solved in magnetic flux coordinates using matrix implicit methods. An arbitrary transport model can be used. Neoclassical-resistivity, bootstrap-current, auxiliary-heating, current-drive, alpha-heating, radiation, pellet-injection, sawtooth, and ballooning-mode transport models are all available. As an option, circuit equations are solved for all the poloidal field coil systems with the effects of induced currents in passive conductors included. Realistic feedback systems can be defined to control the time evolution of the plasma current, position, and shape. Open field lines can be included, and the halo current is computed as part of the calculation.

TSC can be run in several operating modes. The time dependent one-dimensional functions for the pressure $\mathrm{p}(\psi, t)$, the density $\mathrm{n}(\psi, t)$, and the effective charge state $\mathrm{Z}(\psi, \mathrm{t})$ can either be specified as input or be calculated from transport equations, density evolution equations, or impurity transport and ionization physics. The plasma current is calculated self-consistently from the changing external coil currents, with or without feedback systems included. There is also an option to impose symmetry about the midplane or to model the full device with no up/down symmetry.

TSC development has been project driven. Capabilities were added as needed. TSC had its origins in the S-1 spheromak in modeling the inductive formation using a flux core [1]. It was used on the PBX experiment to calculate the effect of strong shaping on plasma axisymmetric stability, disruption forces on the passive stabilizers, volt-second benchmarking, and in modeling the current-drive experiments [2]. It was used on the TCV experiment for the design of a tokamak with a flexible shaping system, and to study doublet formation [3]. For CIT and Ignitor, 
it has been used to compute volt-second consumption, disruption effects, and the possibility of transient ignition [4]. TSC has been used in modeling shape control, VDEs, and volt-second benchmarking in the DIII-D experiment [5]. Burn control feedback and the capability of diverter sweeping were added for the BPX experiment [6]. TSC was used extensively on TPX for vertical control, shape control, and for developing plasma scenarios [7]. For ITER, TSC was used to compute volt-second consumption and shape control, and to develop plasma disturbances for evaluations of the control system [8]. The ohmic phase of TFTR was used to benchmark TSC [9] and the Krypton impurity injection experiments were also modeled [10].

We show in Figure 1 the results of using TSC to model a NSTX discharge, shot 100920.

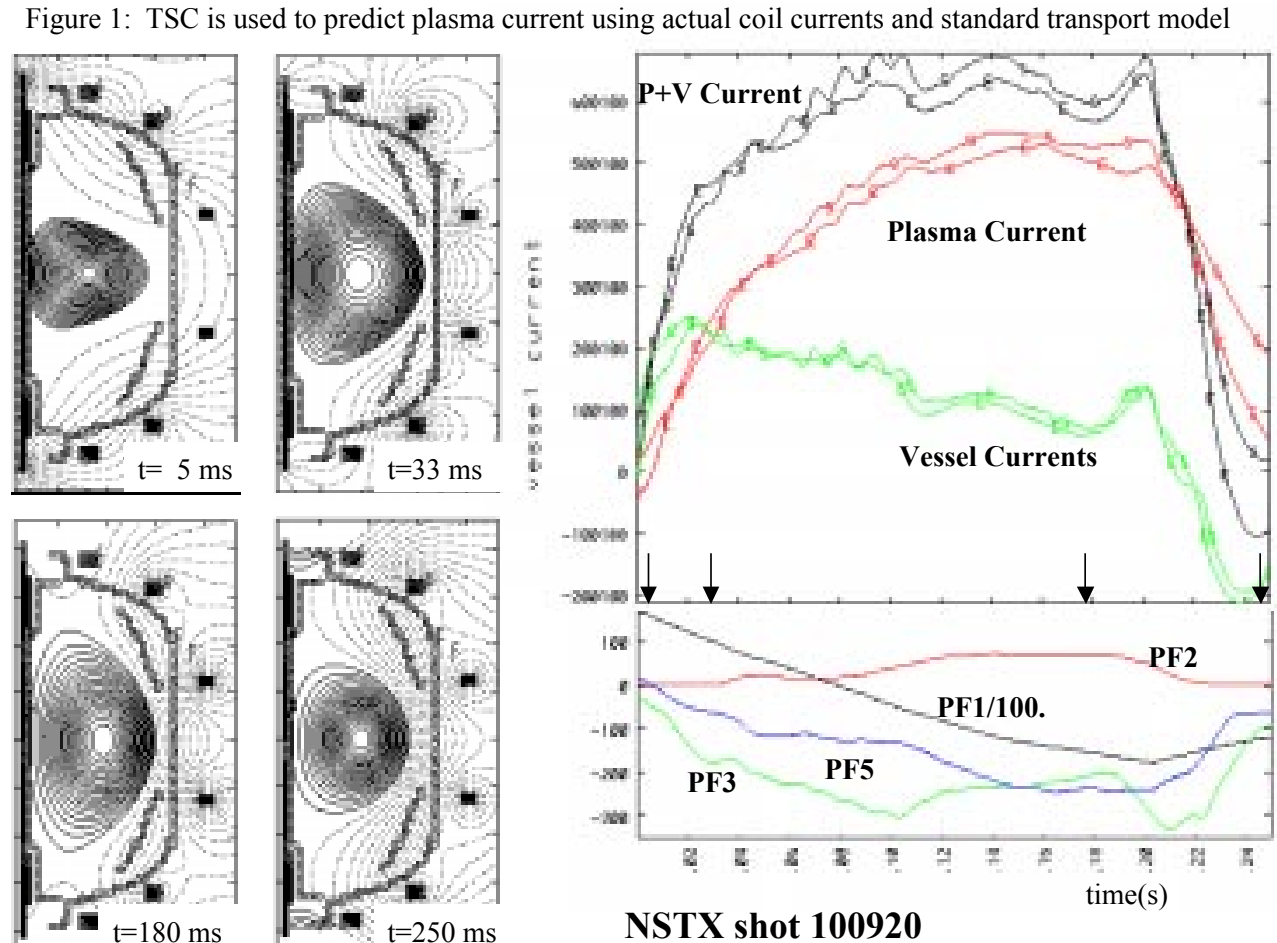

Comparison of the TSC predicted flux loop values with the experimental values shows very good agreements. TSC predicts that the current density in this case is slightly hollow during the rampup, peaked during the flattop, and remains peaked during the decay. The loop voltage becomes flat near the end of the flattop at about $1.5 \mathrm{~V}$. In this case, the peak electron temperature is computed to be about $900 \mathrm{eV}$, and the plasma $\beta$ peaks at about $1.4 \%$. A multiplicative factor of 1.5 was applied to the "standard" TSC transport coefficients [9] with $10 \%$ carbon impurity $\left(\mathrm{Z}_{\mathrm{EFF}}=2.7\right)$ and $<\mathrm{n}_{\mathrm{e}}>\sim 0.7 \times 10^{19}$ to obtain this agreement. Almost identical agreement was obtained in another run with a multiplicative factor of 1.0 but with $90 \%$ carbon impurity $\left(\mathrm{Z}_{\mathrm{EFF}}=5\right)$.

Figure 2 illustrates the application of TSC to a NSTX 1 MA shot, number 101522 using the standard model with multiplicative factor of 1.0 and with $20 \%$ Carbon $\left(Z_{\text {EFF }}=3.7\right)$ and $<n_{e}>=2.5 \times$ $10^{19} \mathrm{~m}^{-3}$. In this discharge, the plasma current never totally equilibrates and stays slightly hollow 
until termination. Examining the ballooning mode stability of this discharge with DCON and the TSC balloon stability package shows that a region of balloon stability develops near the $\mathrm{q}=1$ surface just before the discharge terminates

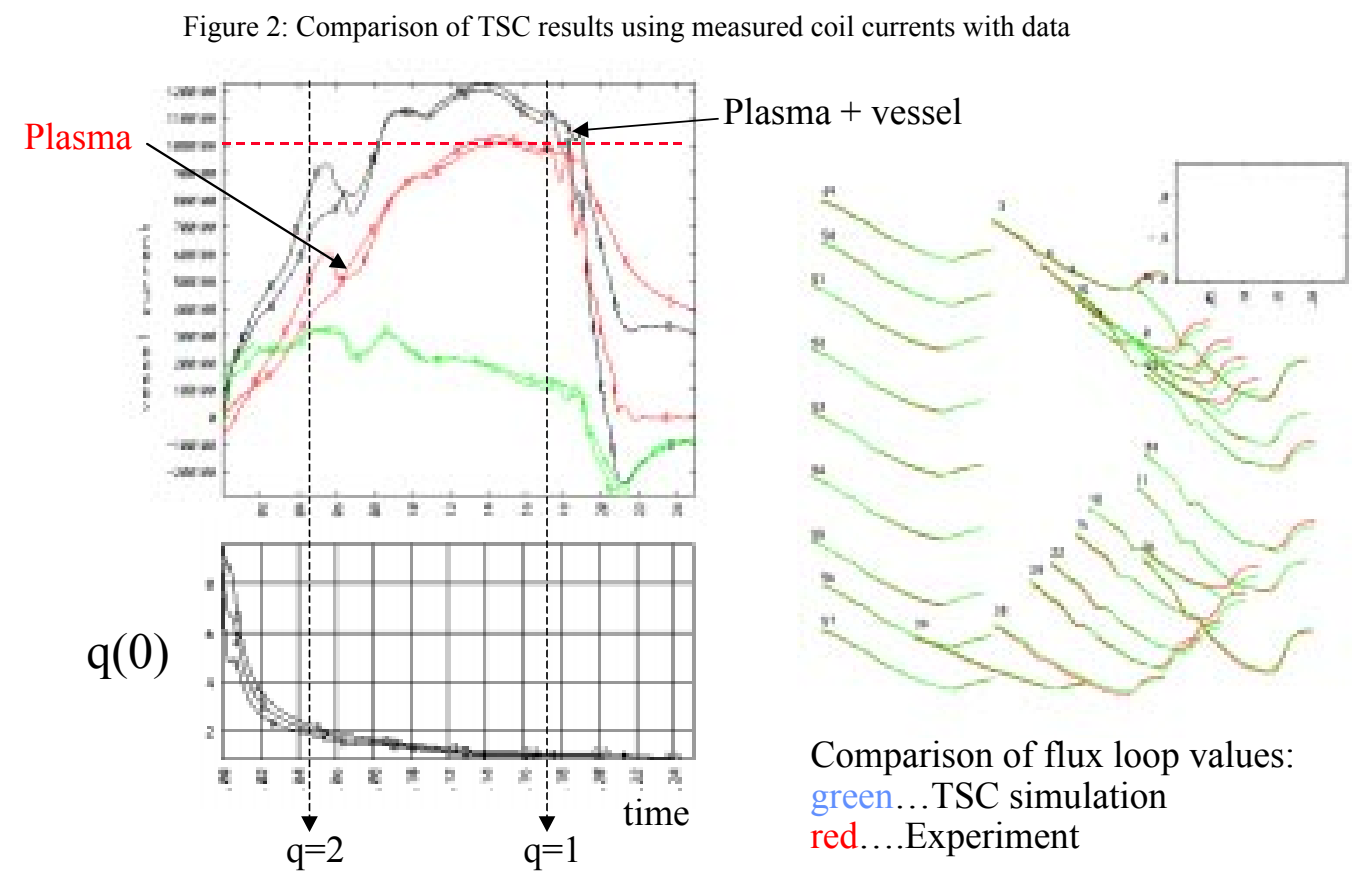

Shot 101522

We have extended this analysis to attempt to predict the consequences of if we had added neutral beam heating to shot 101522 . The plasma current was ramped to $1 \mathrm{MA}$ in $0.12 \mathrm{~s}$, with $2 \mathrm{MW}$ of beams turned on at $70 \mathrm{~ms}$ and this increased to $5 \mathrm{MW}$ at $100 \mathrm{~ms}$. TSC +DCON predict this would get to about $\beta>15 \%$ energetically, but that a region of balloon instability develops shortly after the full $5 \mathrm{MW}$ of beams are turned on. The instability that sets in at about $\beta=12 \%$ is due to the low shear near the $\mathrm{q}=1$ surface, together with the peaked pressure profiles there.

Figure 3: Contours of toroidal current, poloidal current stream lines, and poloidal magnetic flux contours at end of CHI discharge with total plasma toroidal current $148 \mathrm{kA}$.

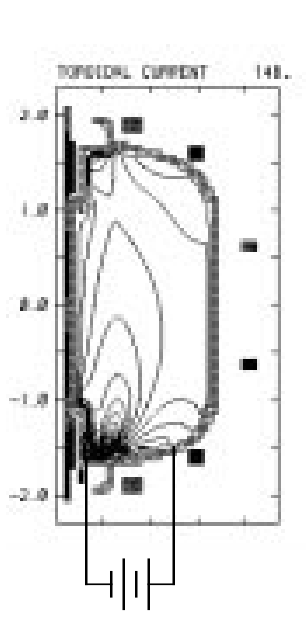

$\mathrm{RB}_{\mathrm{T}}$
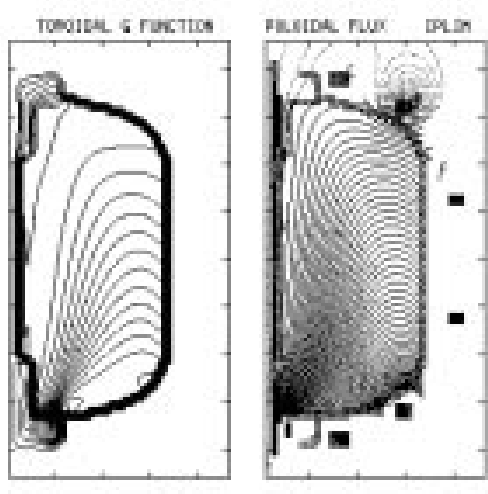

Shot 102080
As a final application of TSC to NSTX, we have performed modeling of the Coaxial Helicity Injection (CHI) experiments. In this modeling, the NSTX vacuum vessel is modeled as a metallic structure with poloidal breaks at the top and bottom[11]. An electric potential $V$ is applied across the break as illustrated in Figure 3. Again, we used the same poloidal field (PF) coil currents as were used in NSTX Shot 102080. Due to the difficulty in computing the actual plasma resistance including the plasma-vessel sheath resistance in this 
case, we did not attempt to use the experimentally measured voltage, but rather applied a constant voltage $V$ across the lower vessel gap and adjusted this value $V$ to give approximate agreement with the measured toroidal current. In Figure 4 we illustrate the agreement of the TSC calculations of the $\mathrm{CHI}$ experiment and the experimental data. We find that the poloidal flux surfaces are significantly distorted by the $\mathrm{CHI}$ induced toroidal currents, but TSC does not predict any closed flux surfaces for these shots.

Figure 4: TSC currents and fluxes compared with experimental data.
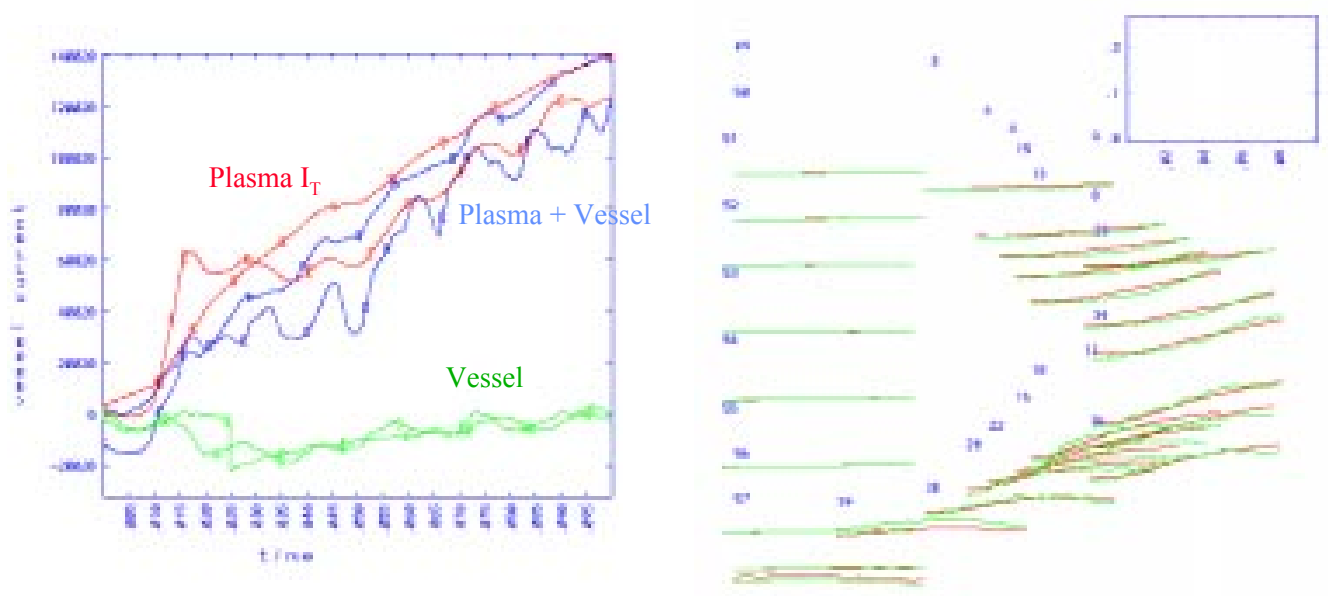

Shot 102080

Based on the encouraging agreement between the TSC results and the initial NSTX data, we plan to continue to use TSC to guide and interpret the NSTX data during the next run period.

Acknowledgements: The authors are grateful to Dr. M. Peng, M. Ono, and R. Goldston for useful discussions, support, and encouragement. This work was supported by DoE contract \# DE-AC02-76-CHO-3073.

\section{References:}

[1] S.C. Jardin, W. Park, Phys. Fluids, 24, 679 (1981)

[2] S.C. Jardin, J. DeLucia, M. Okabayashi, et al., Nucl. Fusion 27, 569 (1987)

[3] F.B. Marcus, S.C. Jardin, and F.Hofmann, Phys. Rev. Lett. 55, 2289 (1985)

[4] D. Post, et al., Physica Scripta. T16, 89 (1987)

[5] R. Sayer, Y.-K.M. Peng, S.C. Jardin, 33, 969 (1993)

[6] S.C.Jardin, M.G.Bell, et al., Fusion Technology, 21, 1123 (1992)

[7] J.A. Schmidt, et al., J. of Fusion Energy, 12, 221 (1993)

[8] S.C. Jardin, C.E. Kessel, N. Pomphrey, Nucl. Fusion, 34, (1994)

[9] S.C. Jardin, M.G. Bell, N. Pomphrey, Nucl. Fusion, 33, 371 (1993)

[10] S.C.Jardin, G.L.Schmidt, et al., Nucl. Fusion, 40, 923 (2000)

[11] S.C. Jardin, J.A. Schmidt, Nucl. Fusion, 38, 1105 (1998) 
The Princeton Plasma Physics Laboratory is operated by Princeton University under contract with the U.S. Department of Energy.

\author{
Information Services \\ Princeton Plasma Physics Laboratory \\ P.O. Box 451 \\ Princeton, NJ 08543
}

Phone: 609-243-2750

Fax: 609-243-2751

e-mail: pppl_info@pppl.gov

Internet Address: http://www.pppl.gov 